\title{
Gastrointestinal stromal tumour (GIST) from the point of view of a general surgeon
}

\author{
Hutan M Sr${ }^{1}$, Hrusovsky A², Hutan M Jr \\ ${ }^{1}$ IVth Department of Surgery, Faculty of Medicine, Comenius University and University Hospital Bratislava. \\ martin.hutan@ruzinov.fnspba.sk
}

\begin{abstract}
Authors present the current knowledge about pathology of gastrointestinal stromal tumours (GISTs), their symptoms and diagnostics. They present data about surgical and biological therapy of GISTs and relation between them based on literature. This work is supplemented with the own group of 16 patients with GISTs, treated on their surgical ward in years 2003-2008. General surgeon meets GISTs in unclear diagnosed tumours and when encountering their complications. Recurrent and metastatic tumours should be treated in centres (Tab. 6, Fig. 1, Ref. 24). Full Text in PDF www.elis.sk.

Key words: GIST, gastrointestinal stromal tumour, imatinib, surgical therapy, biological therapy.
\end{abstract}

GIST (Gastrointestinal Stromal Tumours), previously classified as leiomyomas, leiomyosarcomas, or aggressive neurinomas, are rare tumours of gastrointestinal tract of mesenchymal origin. Their classification as stromal tumours was introduced by Mazur and Clark (1983) based on the knowledge that these tumours are a distinct clinical-pathological entity (1). From 1988 on are GISTs defined by the expression of mutated KIT (CD 117), receptor of stem cells (SCF - Stem Cell Factor) and detached from tumours of smooth muscle. C-kit gene is a proto-oncogen, which codes KIT protein (transmembranous tyrosinkinase receptor (2)). C-kit protein (known as antigen CD 117) is found in the interstitial cells of Cajal, which GIST originate from. KIT is functional in differentiation of cells, growth and survival. Mutation of KIT gene in GIST leads to activation of KIT protein, result of this being an uncontrolled stimulus of cell proliferation. Summing up, the result is over-expression of tyrozine KIT receptor. Mutation of KIT gene can be identified in 75-90 \% of GISTs. Mutations ale almost always sporadic, since familiar occurrence is rare (3). GISTs are rare, with the prevalence of $1.5-2$ patients $/ 100000$ people (4), occurring more often in females $(5,6)$. The average age is between 55 and 65 years, in females is the average age higher.

The aim of our work was to evaluate our experience with the management of GISTs at the IVth Department of Surgery of Medical Faculty Comenius University and University Hospital Bratislava (IVth Department of Surgery). The aim of this clinic is general surgery, vascular surgery and thoraco-abdominal trauma-

${ }^{1}$ IVth Department of Surgery, Faculty of Medicine, Comenius University and University Hospital Bratislava, ${ }^{2}$ Alpha Medical Pathology, s.r.o. - Diagnostic Centre, Ruyinov, Bratislava, and ${ }^{3}$ IInd Department of Surgery, Faculty of Medicine, Comenius University and University Hospital Bratislava, Slovakia

Address for correspondence: M. Hutan, MD, IVth Department of Surgery, Faculty of Medicine, Comenius University and University Hospital Bratislava- Ruzinov, Ruzinovska 6, SK-826 06 Bratislava, Slovakia. tology with acute cases, mainly acute abdomen, being a significant percentage of our patients.

\section{Material}

16 patients with histologically verified GISTs were managed at the IVth Department of Surgery during years 2003 to 2008. In ten cases, GIST was localized in stomach, in five in small intestine, and once from rectum in rectovaginal septum. The group consisted of nine male and seven female patients aged 43-86 with the average age 65 years. Distribution based on tumour localization is in the Table 1.

Ten patients were operated on electively, out of these in eight cases with a suspected GIST. In the rest of electively operated patients (two), GIST was diagnosed accidentally (tumour of coecum and adnexes). Five patients were operated on urgently for bleeding, one semi-urgently after a bleeding, stabilisation of the patient and completion of diagnosis. Distribution of patients based on indication is shown in the Table 2.

Tab. 1. Distribution of GISTs in group of patients.

\begin{tabular}{lc}
\hline Localization & Number \\
\hline stomach & 10 \\
small intestine & 5 \\
rectum - rectovaginal septum & 1 \\
total & 16 \\
\hline
\end{tabular}

Tab. 2. Indication for operation.

\begin{tabular}{lc}
\hline Indication for operation & Amount \\
\hline urgent - for bleeding (stomach, small intestine) / & 5 \\
semiurgent - after stabilisation after bleeding & 1 \\
elective - suspition for GIST & 8 \\
elective - accidental finding (tumor of coecum, tu adnexes) & 2 \\
total & 16 \\
\hline
\end{tabular}


Tab. 3. Types of operation for GIST.

\begin{tabular}{lc}
\hline Type of operation & Amount \\
\hline Excision of wall of stomach with tumor & 5 \\
Billroth II resection of stomach & 3 \\
Proximal resection of stomach & 1 \\
Total gastrectomy & 1 \\
Resection of small intestine & 5 \\
Low anterior resection of rectum & 1 \\
Multiorgan resection (small intestine, urinary bladder, appendix) & 1 \\
Resection of liver & 1 \\
Cryodestruction of liver metastases & 1 \\
Total & 19 \\
\hline
\end{tabular}

In 16 patients, 19 operation have been performed. In three patients after a resection of stomach, later on, a multiorgan resection was indicated (small intestine, appendix, urinary bladder), resection of liver and a cryodestruction of metastases in liver. The types of operation and their numbers are shown in the Table 3.

Authors did not indicate a laparoscopic approach in these patients, so all operations were performed by an open technique. In histological findings, screw-like cell type was found in 11 cases, epithelial variant in 2 cases, and combined type in 2 cases. In these findings, different mitotic activity and diverse imunohistochemical profile was found (differences between positivity of CD 117 (ckit), CD 34. In last years, all samples are sent for genetic examination and confirmation to the reference centre in Martin, Slovak Republic. Afterwards, patients were consulted with oncologist about latter treatment and follow up.

No patient died during an early postoperative period (30 days), one patient after a resection of small intestine was re-operated due to a dehiscence of anastomosis.

\section{Discussion}

In GISTs, transformation of interstitial cells of Cajal is happening, with mutating activation of two basic genes - KIT and PDGFRA.

KIT is one of the type III receptors of tyrosinkinase, prolonged activation of which, based on molecular-genetic changes, results in development of GIST. An effective therapy of locally advanced and metastatic tumours by inhibition of this thyrosinkinase is available.

Almost all GISTs express c-kit (CD 117), approximately 70 $\%$ express CD 34, which is a marker of endothelial cells and hematopoietis stem cells. Imunohistochemical characteristics are related to Cajal cells, cells that assign intestinal motorics. Distribution of GISTs based on literature $(4,7)$ is in the Table 4 . These tumours can be localized extraintestinaly in mesentery, omentum, or retroperitoneum.

Histologicaly, these tumours are characterised by screw-like cells, epithelial type cells, or have mixed characteristics, that resemble stromal components of different organs in the gastrointestinal tract. This is the reason why these were defined as leiomyomas, leiomyosarcomas or schwannomas.

The risk of malignity depending on the size and mitotic activity is in the Table 5 (8). In new publications, new factors of malignity are identified, such as localization (9), overgrowth through
Tab. 4. Distribution of GIST based on literature $(4,7)$.

\begin{tabular}{lc}
\hline Organ - localization & Distribution \\
\hline Oesophagus & $1 \%$ \\
Stomach & $51 \%$ \\
Small intestine & $36 \%$ \\
Large intestine & $7 \%$ \\
Rectum & $5 \%$ \\
Extraintestinal & under $1 \%$ \\
\hline
\end{tabular}

Tab. 5. Risk of maliginity of GIST (8).

\begin{tabular}{lll}
\hline Risk of malignity & Size of tumor & Number of Mitose \\
\hline Very low & Less than $2 \mathrm{~cm}$ & Less than $5 / 50 \mathrm{HPF}$ \\
Low & $2-5 \mathrm{~cm}$ & Less or equal $5 / 50 \mathrm{HPF}$ \\
Intermediate & Less than $5 \mathrm{~cm}$ & $6-10 / 50 \mathrm{HPF}$ \\
& $5-10 \mathrm{~cm}$ & Less or equal $5 / 50 \mathrm{HPF}$ \\
High & More than $5 \mathrm{~cm}$ & More than $5 / 50 \mathrm{HPF}$ \\
& More than $10 \mathrm{~cm}$ & Any mitotic count \\
& Any size & More thna $10 / 50 \mathrm{HPF}$ \\
\hline
\end{tabular}

serosa, intact capsule of tumour, and mutation state based on mutation analysis of KIT and PGFRA (platelet derived growth factor receptor alfa) genes (10). An important factor of bad prognosis is perioperative tumour rupture.

\section{Symptoms and diagnosis}

Symptoms of GIST tumours are following:

1. asymptomatic - Tumours might create no symptoms until the size of app. $10 \mathrm{~cm}-20 \%$ of patients,

2. non-specific symptoms - Diagnostics often find a palpable mass in the abdominal cavity, which is associated with pain,

3. locality dependent symptoms - Patients experience specific symptoms based on localization of GIST: oesophagus - dyspepsia, stomach - anaemia, small intestine - stool passage dysfunction, abdominal pain or dyscomfort, quick surfeit, obstructive icterus, fever, symptoms associated with anaemia - fatigue, palpitations (11),

4. acute abdomen - Patients with GIST often present with the signs of an acute abdomen:

- $25 \%$ - bleeding to gastrointestinal tract (melena, enterorhagia), peritoneal cavity (12),

- less than $10 \%$ - perforations of GISTs $(13,14)$,

- rarely - ileus of small intestine.

The Carneys trias has been described, with an unknown pathogenesis and consisting of: ventricular, typically epithelial cell like GIST, extra-adrenal paranganglioma, and lung chondroma.

When a suspicion od GIST is raised, following examinations should be performed:

1. endoscopy - ulceration or necrosis, though intact mucosa is possible, EUS (endoluminal sonography),

2. CT and MRI - also with use of gadolinium contrast,

3. X rays of gastrointestinal tract,

4. PET (Positron Emission Tomography) - Intensive take-up of FDG (Florine-deoxy-glucose) has been described.

When diagnostics is under way, physicians has to have a possible GIST on their mind. Percutaneus or peroperative biopsy is 
not recommended, since tumours are well vascularised and fragile and such biopsy might lead to tumour rupture, bleeding, and tumour dissemination. If biopsy is done, often non-representative sample of necrotic tissue is collected.

\section{Therapy}

Therapy of GISTs is possible in general hospitals without any problems (6). It is necessary to distinguish therapy of primary tumours from therapy of advanced metastatic and recurrent GISTs.

The strategy of therapy is dependent on the effectiveness of therapy with imatinib - mesylate, which is tyrosinkinase inhibitor.

Primary GIST without the signs of metastasis should be treated by surgical resection with an effort of complete resection (R0). Operation type is dependent on the locality of tumour - tumour of small intestine is solved by segmental resection with $2-5 \mathrm{~cm}$ safe border, similarly, tumours of colorectum are treated with segmental resection. No lymphadenectomy is necessary since GISTs do not metastase into lymphatics. In selected cases of low rectal GISTs, abdominoperineal amputation is required.

In GISTs of stomach, the size is what matters. In tumours of approximately $3 \mathrm{~cm}$ in size or in pedunculated tumours, a resection of wall of stomach with up to now not clearly stated border is sufficient. Depending on localization, laparoscopic resection is feasible $(15,16)$. Proximal or distal resection of stomach with gastroduodenostomy or oesophagogastroanastomosis after tubula- tion is done in larger tumours. Bilroth II type stomach resection is done less often. Very small tumours up to $2.5 \mathrm{~cm}$ are possible to enucleate without significant complications endoscopically (17). Golden standard, consisting of a complete transperitoneal excision (open or laparoscopic) with clear margins and without tumour rupture, dominates therapy of gastric GISTs

Total subdiafragmatic gastrectomy is recommended for tumours close to gastroesophageal junction.

In cases, when GIST of duodenum needs to be removed, duodenopancreatectomy is indicated, even though simple segmental resections of second part of duodenum have been described (19).

Fundamentals of surgical technique according to Cameron (3) are: 1. exact assessment of the presence of metastases,

2. light-handed technique - Tumours are fragile and ,parasite“ on blood supply of adjacent structures. GIST case is easily torn and bleeding, with a possibility of tumour rupture. GIST tumours usually don't invade organ diffusely, they often protrude from gastrointestinal tract. Simple enucleation should not be done, segmental resection should have $1-2 \mathrm{~cm}$ microscopically free marging. An advantage of wider resection margins is not stated. Because of rare metastatics to lymphatics, lymphadenectomy is rarely necessary, positive lymphatics usually indicate satelite tumours. In case of an incomplete resection (R1) imatinib therapy or completion of surgical resection is indicated.

Metastatic GISTs are found in $47 \%$ of patients. Basis of therapy consists of imatinib mesylate, which induce remission in

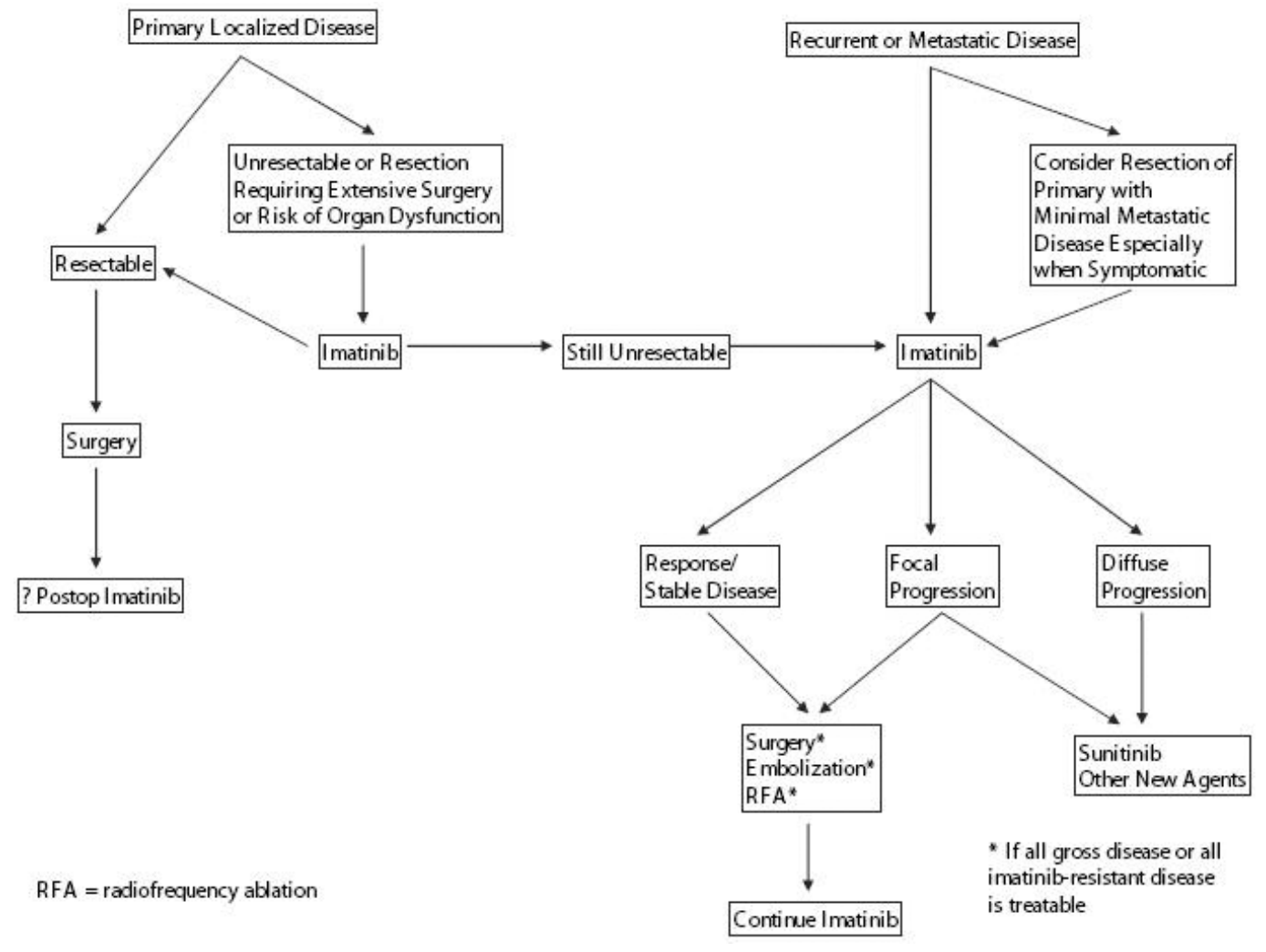

Fig. 1. Algorithm by Gold and De Matte (Gold, 2006). 
Tab. 6. Key principles in treatment of GISTs (24).

\begin{tabular}{ll}
\hline Clinical finding & Therapy \\
\hline Localized disease - one tumor & $\begin{array}{l}\text { Complete surgical extirpation with microscopicall free margins, avoiding rupture of the tumor, } \\
\text { neoadjuvant therapy for organ salvage, adjuvant therapy in tumor rupture }\end{array}$ \\
Recurrent or metastatic disease & $\begin{array}{l}\text { Imatinib until treatment failure, surgical resection of residual tumor (with unclear benefit), } \\
\text { necessity of disposal of bleeding, infected, and obstructing metastases - tumors } \\
\text { GIST progression despite imatinib therapy }\end{array}$ \\
& $\begin{array}{l}\text { Elevation of imatinib dosage ( } 800 \text { mg), surgery for solitary metastasis, sunitinib or new me- } \\
\text { dicaments, surgery or radiotherapy in selected patients }\end{array}$ \\
\hline
\end{tabular}

$50-70 \%$ of patients. Imatinib resistance remains a problem. The most common mechanism of imatinib resistance is a presence of another mutation in KIT kinases domenes. These secondary mutations might vary in various metastases, resulting in possibility that progression of disease will be seen in selected localizations (20). Heterogenity of resistant tumours remain the main problematic issue. Differently mutated cells in various locations make this resistant disease hard to manage. In these cases, multikinase inhibitor (sunitinib) or other medicament (heat shock protein 90 - HSP 9) or others (21) can be used.

Metastases are almost solely found in liver and peritoneal cavity. Metastatic disease of lungs and CNS (central nervous system) are extremely rare and metastases in bones are usually asymptomatic. Imatinib administration is the standard treatment in therapy of metastatic disease, multiorgan resections might be needed if the response is inadequate. Treatment options in the metastatic disease of liver are resection, radiofrequency ablation, cryodestruction etc. Japanese authors published a study with a group of 16 patients with disease progression, treated by resection of liver, radiofrequency ablation, or the combination of these two. Liver transplantation is not recommended even in diagnosed isolated liver metastatic disease.

In cases of advanced tumours and unclear diagnosis, multiorgan or extended resections of stomach, duodenum, proximal jejunum, left colon, and rectum take place. Recurrence of the disease with the need of adjuvant therapy comes often into place in undiagnosed dissemination. In advanced disease without CT, MRI, or PET signs of a distant metastasis is thus recommended administration of imatinib for three months following a control of the response. Operation is recommended in patients with an inadequate response as well as in patients with positive response, that we might consider as neoadjuvant treatment.

Neoadjuvant treatment is thus indicated:

1. in non-resectable tumour in which we assume that imatinib administration could lead to a potential resection,

2. in locally advanced tumours, in which radical operation would be mutilitating (amputation of the rectum, surgery of the oesophagus, duodenopancreatectomy (21)).

\section{Surgical treatment of complications of GISTs}

Palliative surgical treatment comes into place if complications, such as obstruction and bleeding, occur.

Recurrent disease is being described approximately two years after resection. New mutations of individual tumours are possible.
The prognosis of disease got better with the administration of imatinib, dosage of which should be doubled if symptoms of the tumour are being developed. PET scan to assess, whether it is a well bordered operable tumour and not a progressing multifocal disease, should be done preoperatively. In these cases, the resection of residual tumour carry an acceptable morbidity (23). We have to stress, that in advanced and metastatic disease, biological therapy should not be postponed because of surgical therapy, and that cytoreduction does not lead to amelioration of an overall survival.

Algorithm by Gold and De Matte (Gold, 2006) is shown on the Figure 1 (24).

Key principles of treatment of GISTs are in the Table 6 (24)

\section{Surgical treatment of imatinib complications}

Typical complications of cytotoxic chemotherapy, such as leukopenia, thrombocytopenia, and diarrhoe are not present. Despite this, bleeding complications, hypertension, and hyperfibrinolysis might occur. Cessation of imatinib treatment for 24 hours before a planned operation is needed, with an anticipated normalisation of D-dimer values. Pre-therapy proliferation tumour activity within 7-14 days after imatinib cessation can be anticipated. Intratumour or intraabdominal bleedings are not uncommon. The indication for hematoma evacuation of hypervascularised GISTs is dependable on hemodynamics and should be done within 48-72 hours. Surgical treatment consists of clearing the hematoma, tamponade of abdominal cavity and eventual drainage. A lavage of abdominal cavity might also permit control of peritoneal contamination (5). No evidence of an unfavourable course of disease as a result of GIST rupture during imatinib treatment is known.

\section{Conclusion}

The presented group of patients is small, it is more a case series. From the point of view of a general surgeon it is needed to say that mainly the complications of GISTs are managed on the general surgical wards, where patients are admitted as surgical emergencies. Similarly, on the Department of Surgerys with an experience of more extensive operations are patients with GISTs admitted and electively operated despite unclear findings. It could be favourable to concentrate patients with diagnosed GISTs in centres, although opinions of various authors are, that well established general hospital is able to manage patients with a primary disease completely. Metastatic and recurrent disease should be treated in centres in close cooperation with a clinical oncologist. 


\section{References}

1. Cipková A. Gastrointestinal Stromal Tumour-Complex View on diagnostic and Therapy. Onkologia (Bratislava) 2010; 3 (6): 372-376.

2. Hirota S, Isozaki K, Moriyama Y et al. Gain of function mutations of ckit in human gastrointestinal stromal tumours. Science 1998; 279: 577-580.

3. Cameron JL. Current Surgical Therapy. Baltimore: Elsevier-Mosby, 2004, 1400 pp.

4. Nillson B, Bumming P, Meis-Kindblom JM et al. Gastrointestinal stromal tumours: the incidence, prevalence, clincal course, and prognostication in the preimatinib mesylate era - a population-based study in western Sweden. Cancer 2005; 15 (4): 821-829.

5. Hohenberger P, Wardelmann E. Gastrointestinale Stromatumouren. Was der Chirurg wissen muss. Chirurg 2006; 77: 33-40.

6. Machado-Aranda D, Malamet M, Chang YJ, Jacobs MJ, Ferguson L, Silapaswan S, Goriel Y, Kolachalam R, Mittal VK. Prevalence and Management of Gastrointestinal Stromal Tumours. Am Surgeon 2009; 75 (1): 55-60.

7. Tran T, Davila J, El-Serag HB. The epidemiology of malignant gastrointestinal stromal tumours. An analysis of 1458 cases from 1992 to 2000. Am J Gastroenterol 2005; 100: 162-168.

8. Fletcher CDM, Berman JJ, Corless C, Gorstein F, Lasota J, Longley BJ, Miettinen M, O'Leary TJ, Remotti H, Rubin BP, Shmookler B, Sobin LH, Weiss SW. Diagnosis of Gastrointestinal Stromal Tumours - A Consensus Approach. Int J Surg Pathol 2002; 10 (2): 81-89.

9. Miettinen M, Lasota J. Gastrointestinal stromal tumours : pathology and prognosis at different sites. Semin Diag Pathol 2006; 23 (2): 70-83.

10. Laurini JA, Carter E. Gastrointestinal stromal tumours. A Review of the Literature. Arch Pathol Lab Med 2010; 134: 134-141.

11. Joensuu H. Gastrointestinal stromal tumour (GIST). Ann Oncol 2006; 17 (Suppl 10): 280-2006.

12. Bucher P, Poletti PA, Myit S, Morel P. Spontaneous rupture of gastrointestinal stromal tumour associates with life-threatening nontraumatic hemoperitoneum. Canad J Surg 2008; 51 (2): E 38-39.

13. Badger S, Yousaf M, Campbell WJ. A case of gastrointestinal stromal tumour presenting as acute abdomen. Irish J Med Sci 2005; 174 (3): 84-85.
14. Efremidou EI, Liratzopoulos N, Papageorgiou MS, Romanidis K. Perforated GIST of the small intestine as a rare cause of acute abdomen. J Gastrointest Liver Dis 2006; 15 (3): 297-299.

15. Privette A, McCahill L, Borrazzo E, Single RM, Zubarik R. Laparoscopic approaches to resection of suspected gastric gastrointestinal stromal tumours based on tumour localization. Surg Endsc 2008; 22 (2): 487-494.

16. Ji ZL, Li JS, Zhang W. A band lifting assisted method for laparoscopic resection of gastrointestinal stromal tumours on the posterior wall of the stomach. Am Surg 2010; 76 (1): 25-27.

17. Katoh T, Itoh Y, Mohri T, Suzuki H. Endoscopic enucleation of gastrointestinal stromal tumours of the stomach: report of five cases. World J Gastroenterol 2008; 14 (16): 2609-2611.

18. Waterman AL, Grobmyer SR, Cance WG, Hochwald SN. Is endoscopic resection of gastric gastrointestinal stromal tumours safe? Am Surg 2008; 74 (12): 1186-1189.

19. Asakawa M, Sakamoto Y, Kajiwara T, Nara S, Esaki M, Shimada K, Hamaguchi T, Kosuge T. Simple segmental resection of the second portion of the duodenum for the treatment of gastrointestinal stromal tumours. Langenbecks Arch Surg 2008; 393 (4): 605-609.

20. Wardelmann $\mathbf{E}$ et al. Acquired resistance to imatinib in gastrointestinal stromal tumours acused by multiple KTI mutation. Lancet Oncol 2005; 6: 249-251.

21. Sufliarsky J. Advances in treatment of gastrointestinal stromal tumours. Onkologia (Bratislava) 2007; 2 (2): 96-101.

22. Hasegawa J, Kanda T, Hirota S, Fukuda M, Nishitani A, Takahashi T, Kurosaki I, Tsutsui S, Hatakeyama K, Nishida T. Surgical interventions for focal progression of advanced gastrointestinal stromal tumours during imatinib therapy. Int J Clin Oncol 2007; 12 (3): 212-217.

23. Hohenberger $\mathbf{P}$, Bauer $\mathbf{S}$, Schneider $\mathbf{U}$ et al. Tumour resection following imatinib pretreatment in GI stromal tumours. Proc Am Soc Clin Oncol 2003; 22: 818.

24. Gold JS, DeMatteo RP. Combined surgical and molecular therapy the gastrointestinal stromal tumour model. Ann Surg 2006; 244: 176-184.

Received November 11, 2011. Accepted December 13, 2011. 